\title{
Lateral Plantar Arch Reconstruction Using Vascularized Fibula Osteocutaneous Flap
}

Srivatsa M Shet *, Subin Joseph, Kader Kalathingal , Hafiz Muhammed Koyappathody, Srikant Aruna Samantaray and Sameer Latheef Department of Plastic, Reconstructive and Burns Surgery, Baby Memorial Hospital, Mavoor road, Kozhikode, Kerala, India.

*Corresponding author: Srivatsa M Shet, Department of Plastic, Reconstructive and Burns Surgery, Baby Memorial Hospital, Mavoor road, Kozhikode, Kerala, India. ORCID: 0000-0001-8494-8779

Received Date: July 27, 2021; Accepted Date: August 20, 2021; Published Date; August 28, 2021

Citation: Srivatsa M Shet, Subin Joseph, Kader Kalathingal, Hafiz Muhammed Koyappathody, Srikant Aruna Samantaray and Sameer Latheef (2021) Lateral Plantar Arch Reconstruction Using Vascularized Fibula Osteocutaneous Flap. J. Surg Case Repo and Imag. 4(6); DOI:10.31579/2690$1897 / 087$

Copyright: (C) 2021 Srivatsa M Shet, This is an open-access article distributed under the terms of the Creative Commons Attribution License, which permits unrestricted use, distribution, and reproduction in any medium, provided the original author and source are credited.

\begin{abstract}
A Sixteen-year-old male had a road traffic accident resulting in crush and loss of lateral two metatarsals of the left foot. The Lateral plantar arch was reconstructed with a vascularized fibula osteocutaneous flap. Flap survived and partial weight-bearing was started by 3 months and full weight-bearing was started 6-months post-surgery. At a 16-month follow-up patient had a normal gait and integrity of the lateral plantar arch was maintained. Vascularized fibula osteocutaneous flap is an excellent option for one-stage reconstruction of the lateral arch of the foot and gives satisfactory results in terms of functions of foot and in avoiding long-term morbidity.
\end{abstract}

Keywords: foot crush injury, lateral plantar arch, one-stage reconstruction, microsurgical fibula flap

\section{Introduction}

Plantar arches of the foot are a very essential part of the normal gait mechanism. Its dynamicity can particularly be appreciated in dancers and artistic gymnasts. Unfortunately, foot and leg are the most common parts to be injured in a road traffic accident (RTA). Restoration of the function of the foot becomes the priority for a plastic and reconstructive surgeon. Bony defects particularly pose a huge challenge for reconstruction owing to the complex nature of foot skeleton and limited availability of soft tissue in the foot. The most common cause of these injuries being road traffic accidents, they are always contaminated. The resulting soft tissue infection and osteomyelitis complicate the situation making reconstruction more challenging.

The lateral metatarsals (4th and 5th) are an integral part of the three-point support and balancing of the foot, hence its reconstruction is very essential for a near-normal gait. Inadequate reconstruction leads to uneven pressure on the sole further leading to pressure callosities and ulcers. We present a case with a lateral plantar arch defect of foot managed with bony and soft tissue reconstruction.

\section{Case Report}

A 16-year-old boy sustained extensive soft tissue crush injury of left Foot following RTA, with amputation of 5th toe and doubtful vascularity of 4th toe (Figure 1a-c). There was a segmental loss of the 4th and 5th metatarsals of about $8 \mathrm{~cm}$ and Fracture of the 3rd metatarsal which was fixed with $\mathrm{k}$ wire. He underwent multiple debridements and Negative pressure wound therapy (NPWT) dressings supported by culture-sensitive antibiotics. With the improvement of wound bed, 15 days following injury (Figure 1d-e), lateral plantar arch reconstruction by Vascularized fibula osteocutaneous flap (VFOC) was planned and a pre-op Doppler scan was done to locate the perforator vessel providing the skin. 


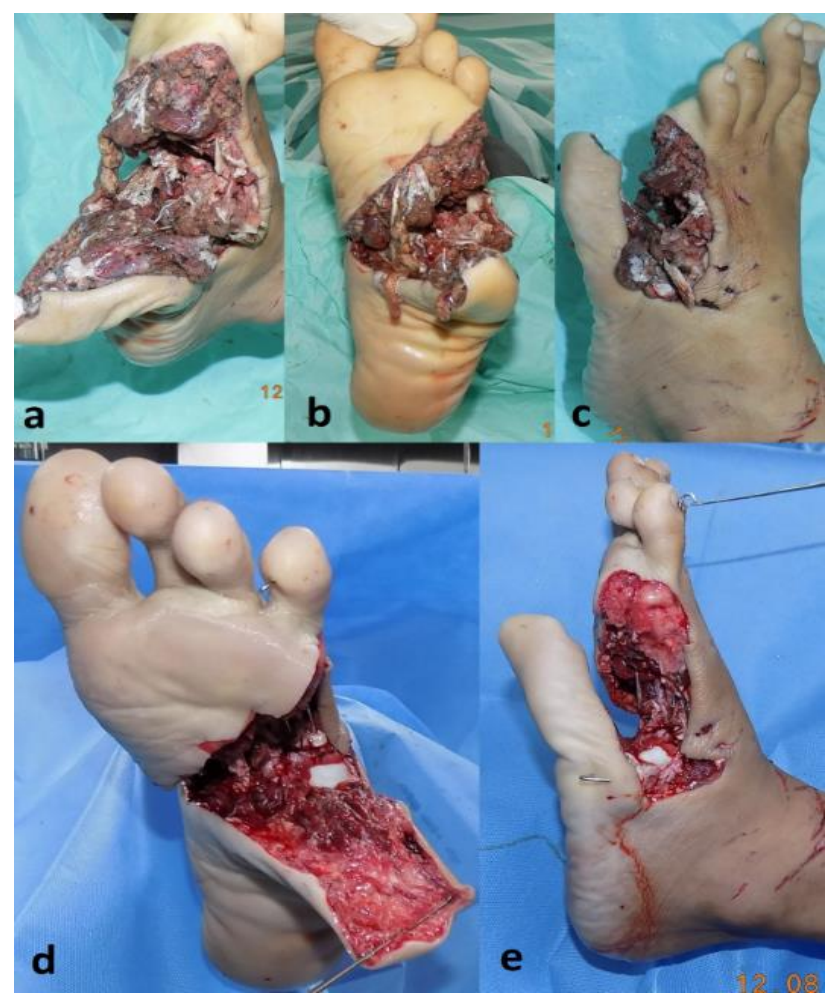

Figure 1. a-c: Severe crushed contaminated injury of left foot with loss of 5th ray, d-e: after thorough debridement.

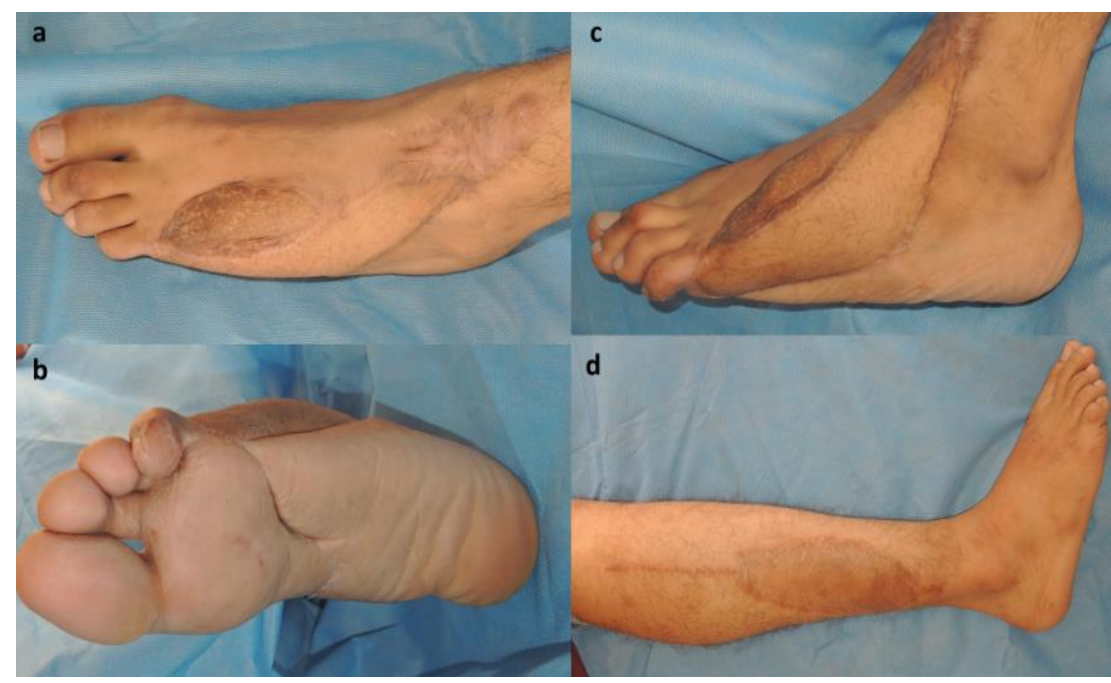

Figure 2. a-c: 16 month post-surgery - well settled flap with supple scars over left foot, d: Right leg lateral view showing fibula flap donor area 


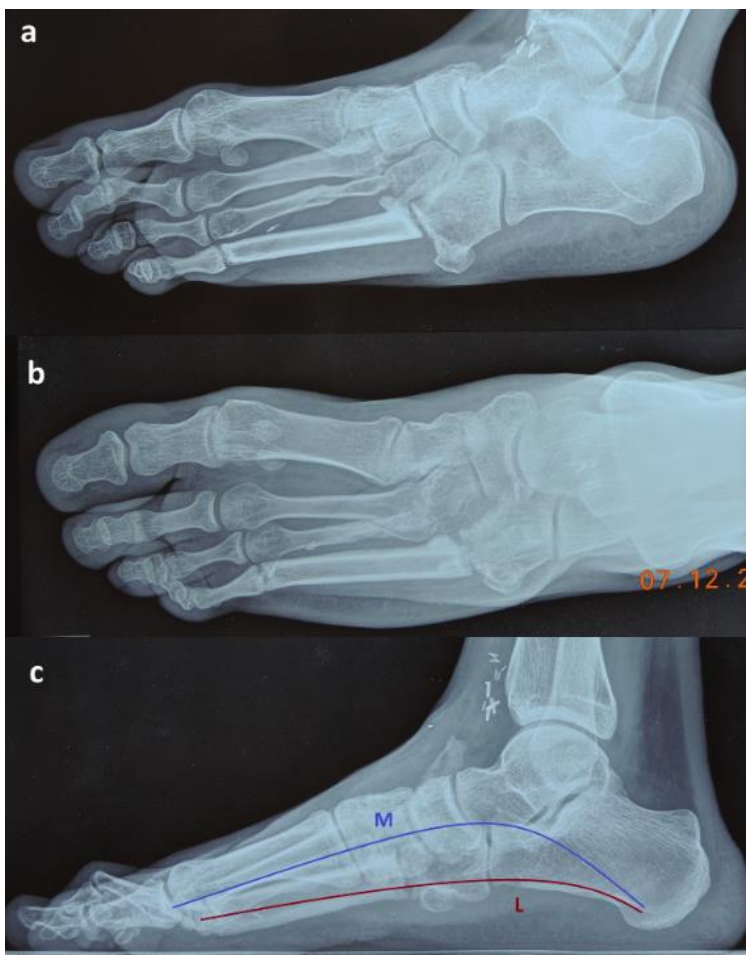

Figure 3. X-ray of reconstructed foot 16 month post-surgery, a,b: Oblique and dorsoplantar views, c: Weight bearing true lateral view showing integrity of lateral $(L)$ and medial $(M)$ plantar arches

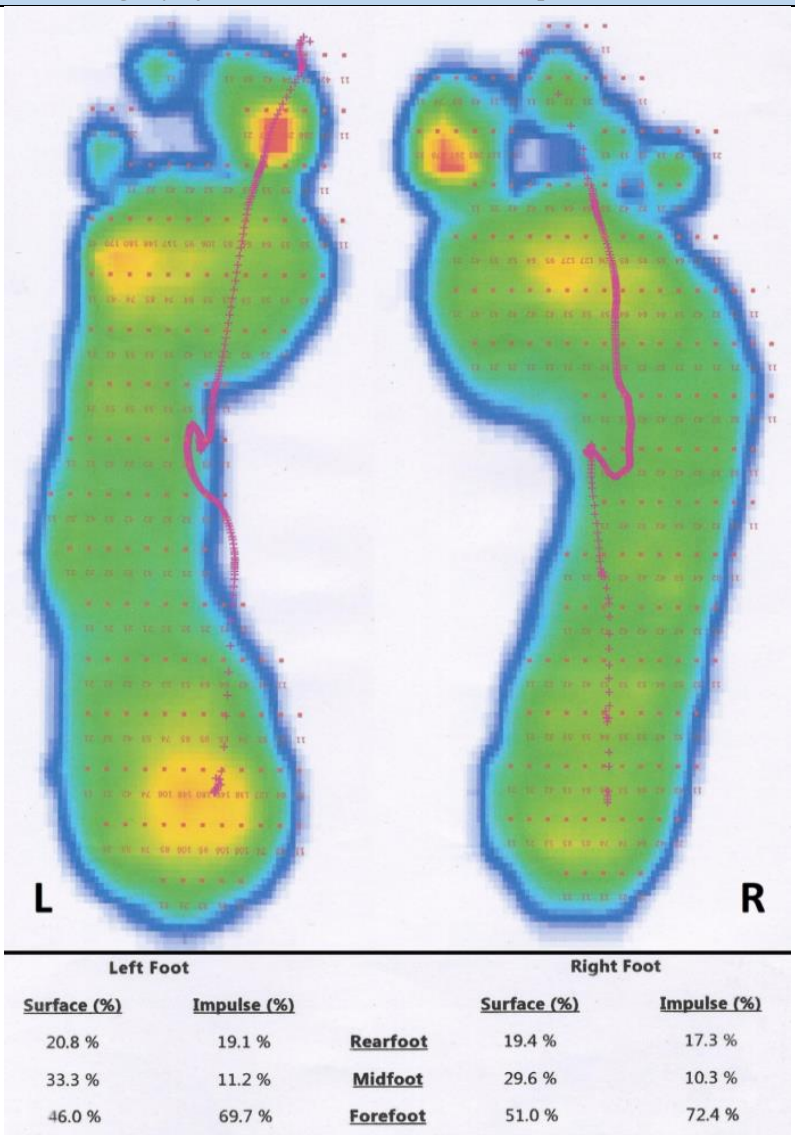

Figure 4. 16month post-surgery Dynamic Pedobarogram. Dotted line marks the Centre of pressure (COP). Colors in the increasing amount of pressure Dark blue < Light blue < Green < Yellow < Red. Below - Comparison of contact percentages. 
Wound bed prepared and markings for flap made on the contralateral leg. Dissection was carried out to preserve the perforators; osteotomy was done $10 \mathrm{~cm}$ above lateral malleolus and $8 \mathrm{~cm}$ below the head of the fibula. Peroneal vessel dissected and ligated at the level of the distal osteotomy. Flap harvested, positioned between the cuboid and proximal phalanx of 4 th toe and fixed with $\mathrm{K}$ wire. Flap pedicle anastomosed to anterior tibial pedicle end to side. Skin paddle inset was given and residual raw areas grafted while flap donor area was primarily closed.

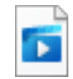

Gait Video.mp4

\section{Video 1. Full weight bearing gait at the end of 16 months}

The standard post-operative care was given like any microvascular flap involving hydration, antiplatelet drugs, and wound care. Flap survived and all wounds healed uneventfully (Figure 2). Splinting was continued for 3 months, $\mathrm{K}$ wires were removed and gait training was started with partial weight-bearing. Full weight-bearing was achieved at 6 months. The patient could return to his previous routine completely within 8 months of surgery. Offloading footwear and silicone sheets were used. At a 16month follow-up, the patient had normal gait (Video) without any donor or recipient site functional limitations. The X-ray showed good bony union and integrity of lateral arch (Figure 3). A dynamic pressure sensing pedobarogram showed no adverse pressure points (Figure 4). His Foot and Ankle Ability Measure - Activities of Daily Living scale (FAAMADL) score ${ }^{1}$ was $82.14 \%$ and he rated his overall current level of function to be $80 \%$ considering his pre-injury function as $100 \%$.

\section{Discussion}

Approach and selection of flap for the complexity of wound:

Wounds of Road traffic accidents have very high chances of infection due to severe crushing of tissues and contamination. Thorough debridement and NPWT help in achieving healthy granulation. Attention to be paid to retain as much plantar skin as possible. The wound in this patient had a loss of the fifth toe and more than $6 \mathrm{~cm}$ defect of fourth and fifth metatarsal bones (part of the lateral arch and lateral aspect of transverse arch of the foot), longitudinal crush laceration of plantar skin along with loss of skin over the lateral half of the dorsum of the foot.

The three arches of foot form a support triangle which is essential for weight-bearing standing and stability of the body. First and fifth metatarsal heads, in particular, take the brunt of weight among the transverse foot arch component, comprising all 5 metatarsal heads [2]. Lateral longitudinal arch has a small arc and is relatively flat when compared to the medial longitudinal arch which has a large arc. Yang et al [2] suggest straight fibular graft for the lateral arch and iliac bone (curved) graft for medial arch reconstruction. There are case reports of medial arch reconstruction also by straight fibular transfer either by pedicled $^{3}$ or free tissue transfer $[4,5]$.

Metatarsal bone has obvious similarity with fibula [6]. As the bone defect was more than $6 \mathrm{~cm}$, vascularized bone graft was indicated [7, 8]. Bringing a vascularized fibula with a cuff of muscle and skin paddle, improves the blood supply of the recipient area, making the surrounding structures also to heal better as well as covering the dorsal skin defect. Plantar skin loss also warrants focus on sensory recovery, often needing a sensate skin flap transfer and neurorrhaphy. As there was no plantar skin loss, these options were not applicable in our case.

Combined soft tissue and bony defects make microsurgical reconstruction more challenging, especially in the foot. The idea of a one-stage reconstruction of bone and soft tissue defect has been propagated owing to its advantages. Yazar et al [8] studied these complex defects with 62 cases reconstructed with composite flaps. The average duration from injury to one stage reconstruction was 27.1 days which is comparable in our case where reconstruction was done after 15 days of the injury.

\section{Intra op customization:}

VFOC flap planning should be meticulous to have appropriate bone length and skin cover. Having said this, the authors opine it is rather good to take a larger chunk of bone with the flap, as intraoperative customization is possible. Similar customizations are described in literature [2,9]. Maximum possible vascular pedicle inclusion is critical as vessels in the recipient site might be at a proximal level than the bone. After positioning the flap in the recipient area adjusting the vessel reach, the excess bone can be osteotomised and used for reconstruction of transverse plantar arch $[2,9]$. Because of the loss of $5^{\text {th }}$ toe, only a single bone segment for the lateral arch was retained and bridged the gap between the 4 th toe proximal phalanx and cuboid bone. One axial k wire to the tarsals and one horizontal to the heads of adjacent metatarsals usually fixes the bone flap. But in our case, horizontal $\mathrm{k}$ wire appeared to potentially disturb the critical blood supply to the surviving toes compelling us to avoid it.

\section{Post-op care and Rehabilitation:}

Dressing changes and Assessment of the vascularity of flap are necessary like in any free tissue transfers. Splint maintains the position of the flap and avoids undue external force. Active movements of the ankle are encouraged at 2 weeks or after wound healing to avoid joint stiffness.

Assessment of the functionality of the reconstructed foot involves multiple parameters. The range of motion of the ankle and the great toe were acceptable with the epicritic sensory recovery of the plantar skin by 16 months. To assess the 3-point support structure, a weight-bearing lateral foot X-ray was obtained as shown (Figure 3). Gait is the common indicator of the adequacy of the procedure, and a near-normal bipedal gait has been shown (Video), which is comparable with results shown by authors who have done fibula flap for lateral plantar arch reconstruction $[2,9]$.

One of the long term complications of any kind of foot injury and reconstruction is the undue pressure on the plantar skin, leading to painful callosities. Yang et al reported that early enthusiastic weight-bearing and activity lead to pressure ulcer and they suggested optimizing the activities [2]. A static and dynamic pedobarogram showed near-normal pressure distribution (Figure 4). Clinically the patient was having a normal bipedal gait and there were no pressure callosities during the 16-month postoperative period ( 8 months of active uninhibited walking). Additionally, we suggest preventive measures like offloading footwear and timely paring of the callosities if any. The early indication for such preventive measures includes painful gait and localized high-pressure points on Static and dynamic pedobarogram.

A VFOC flap is a potential option for salvage of foot and to restore function. This is one of the rare cases of lateral plantar arch reconstruction. With this article, the authors intend to sensitize (i) plastic surgeons towards use of vascularized fibula flap for foot arch reconstruction;

(ii) orthopaedicians and general surgeons for identification and timely referral of similar cases;

(iii) all reconstructive surgeons for continued research in this aspect to strengthen the scientific evidence.

\section{Conclusion}

Lateral plantar arch reconstruction is essential for normal gait and support of the body. Vascularized fibula graft is an excellent option for one-stage 
reconstruction of the lateral arch of the foot and gives satisfactory results in terms of functions of foot and in avoiding long term morbidity.

\section{References}

1. Martin R, Irrgang J, Burdett R, Conti S, Swearingen J. (2005) Evidence of Validity for the Foot and Ankle Ability Measure (FAAM). Foot \& Ankle International. 26(11):968-983.

2. Yang R, Zhou M, Xing C, Li S, Song L, Chen J et al. (2017) Repair of bone defect of the lateral forefoot by double segment triangular fibula flap with vascular pedicle: A case report. Saudi Journal of Biological Sciences. 24(8):1907-1912.

3. Wang C, Han P, Chai Y, Lu S, Zhong W.(2015) Pedicled fibular flap for reconstruction of composite defects in foot. Injury. 46(2):405-410.

4. Salgado C, Lin C, Fuller D, Duncan A, Camison L,(2011) Mardini S. Foot Salvage After Loss of the First and Second Metatarsal Rays with a Free Fibular Osteocutaneous Flap. Journal of the American Podiatric Medical Association; 101(6):531-536.
5. Unal M, Seker A, Demiralp B, Sahin M, Cift H, Oltulu I. (2016)Reconstruction of Traumatic Composite Tissue Defect of Medial Longitudinal Arch with Free Osteocutaneous Fibular Graft. The Journal of Foot and Ankle Surgery. 55(2):333-337.

6. Rajacic N, Ebrahim M, Grgurinovic S, Starovic B. (1996)Foot reconstruction using vascularised fibula. British Journal of Plastic Surgery; 46(4):317-321.

7. Yajima H, Tamai S, Kobata Y, Murata K, Fukui A, Takakura Y. (2002)Vascularized composite tissue transfers or open fractures with massive soft-tissue defects in the lower extremities. Microsurgery; 22(3):114-119.

8. Yazar S, Lin C, Wei F. (2004) One-Stage Reconstruction of Composite Bone and Soft-Tissue Defects in Traumatic Lower Extremities. Plastic and Reconstructive Surgery; 114(6):14571466.

9. Song L, Zhang Z, Wang Y, Liu Y, Liu Z, Chen L et al. (2018) Reconstruction of a Complex Foot Injury With Free Remodeled Fibular Osteocutaneous Flap: A Case Report and Literature Review. The Journal of Foot and Ankle Surgery; 57(3):610-614.
This work is licensed under Creative Commons Attribution 4.0 License

\section{To Submit Your Article Click Here: Submit Manuscript}

DOI: $10.31579 / 2690-1897 / 087$
Ready to submit your research? Choose Auctores and benefit from:

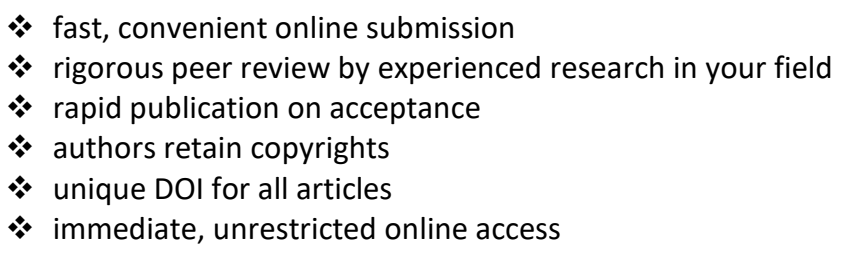

At Auctores, research is always in progress.

Learn more www.auctoresonline.org/journals/journal-of-surgical-casereports-and-images 